\title{
K opisom bolezni in smrti z logičnimi osebki v Slovenskem lingvističnem atlasu 1
}

\author{
Vlado Nartnik
}

Cobiss: 1.03

Prvi zvezek Slovenskega lingvističnega atlasa se nanaša na človeka - na njegovo telo, bolezni in družino. Med imenskimi gesli za bolezni in smrt so posebnost opisi, ki imajo namesto iskanega samostalnika zapisane glagolske frazeme pa tudi elipse z zamolčanim glagolskim jedrom. Glagolska gesla se spet rada vključujejo v stavke s formalnimi in logičnimi osebki.

Ključne besede: opis, formalni in logični osebek, soodvisni, vmesni in dodatni met, osebni in stvarni met, splošnostvarni met

\section{Describing diseases and death using logical subjects in the first volume of the Slovenian Linguistic Atlas}

The first volume of the Slovenian Linguistic Atlas refers to the semantic field 'man'- his body, diseases, and family. Among the nominal entries for diseases and death, descriptions using verbal phrasemes and ellipses more or less lacking the verbal root stand out. Verbal entries tend to be used in sentences with formal and logical subjects.

Keywords: description, formal and logical subject, first, second, and third actant, personal and non-personal actant, ambient actant

\section{Gesla za bolezni in smrt}

Prvi zvezek Slovenskega lingvističnega atlasa se nanaša na človeka - na njegovo telo, bolezni in družino - in obsega 151 gesel (SLA 1.2: 9, 24). Pri tem jih od 129 samostalnikov 18 zaznamuje bolezni in smrt: rana, tvor, mozolj, bradavica, zanohtnica, garje, šen, ošpice, kašelj, nahod, bezgavka, mrzlica, revma, vodenica, jetika, kuga, smrt in mrlič. Sledi 17 pridevnikov in od tega jih 10 zadeva bolezni: zdrav, bolan, slep, gluh, šepav, grbast, suh, debel, trebušast in živčen. Od vsega 5 glagolov pa se dva prav tako nanašata na smrt: umreti in stegniti se.

\section{$1 \quad$ Neglagolska gesla}

Podani pregled sloni na knjižnih vprašanjih, medtem ko je v narečnih odgovorih zlasti na neglagolska vprašanja namesto iskanega samostalnika kdaj pa kdaj zapisan 
$\hookrightarrow \quad$ pridevnik in obratno, tako ob veznem glagolu biti kakor ob sevnem glagolu imeti II (Zimek 1963: 124):

$$
\begin{array}{ll}
\text { vodenica } & \rightarrow \text { biti vodeničen } \\
\text { zdrav } & \rightarrow \text { biti hrust } \\
\text { ošpice } & \rightarrow \text { imeti ven vrženo } \\
\text { trebušast } & \rightarrow \text { imeti trebuh }
\end{array}
$$

Podobna posebnost so opisi, ki imajo namesto iskanega samostalnika zapisane glagolske frazeme pa tudi elipse z bolj ali manj zamolčanim glagolskim jedrom (SLA 1.2: 18, 21):

$$
\begin{aligned}
& \text { revma } \rightarrow \text { trgati po kosteh } \rightarrow \text { po kosteh } \\
& \text { zanohtnica } \rightarrow \text { gnojiti se za nohtom } \rightarrow \text { za nohtom }
\end{aligned}
$$

Še drugačni odmiki v zveze s samostalniki pomenijo gradivo za nove posamostalitve in obratno:

$$
\begin{array}{lll}
\text { suh } & \rightarrow \text { suhega lica } & \rightarrow \text { bleduša } \\
\text { trebušast } & \rightarrow \text { z velikim trebuhom } & \rightarrow \text { trebušon } \\
\text { mrlič } & \rightarrow \text { mrtev človek } & \rightarrow \text { ta mrtvi } \\
\text { smrt } & \rightarrow \text { zadnja ura } & \rightarrow \text { ta zadnja }
\end{array}
$$

Na drugi strani je lahko izpostavljeno ravno glagolsko jedro ter podano v nedoločniku:

$$
\begin{array}{lll}
\text { nahod } & \rightarrow \text { On kiha } & \rightarrow \text { kihati } \\
\text { kašelj } & \rightarrow \text { On kašlja } & \rightarrow \text { kašljati }
\end{array}
$$

\section{Glagolska gesla}

Narečni odgovori na glagolska vprašanja pa se praviloma podajajo v nedoločniku, le da se radi vključujejo $\mathrm{v}$ stavke $\mathrm{z}$ določnimi povedki:

$$
\begin{array}{ll}
\text { stegniti se } & \rightarrow \text { Foter jo je zategnil } \\
\text { stegniti se } & \rightarrow \text { Minilo jo je veselje } \\
\text { tvor } & \rightarrow \text { Nekaj se ji pišči } \\
\text { sirota } & \rightarrow \text { Ni } \emptyset \text { oča, ni } \emptyset \text { matere }
\end{array}
$$

Določni povedki že s protistavo preteklikov je zategnil in minilo je ter sedanjikov piščí, $n i$ in $n i$ kažejo na soodvisnost (S) v času nasproti odvisnosti (O) v kakovosti in kraju:
(S) $k d a j$
(X) koliko
(O) kako
(O) kam ali kje ali kod 
$\mathrm{Na}$ določne povedke se navezuje tudi shajanje in razhajanje med formalnimi in logičnimi osebki (Sicherl - Žele 2012: 51). Skladno s parnimi vprašanji so formalni osebki foter, veselje, nekaj, Ø oča in $\emptyset$ matere še drugače soodvisni s povedki (P), medtem ko so logični osebki jo in se, ji zgolj odvisni od njih:
(S) kdo ali kaj
(X) koga ali česa
(O) koga ali kaj
(O) komu ali čemu

\section{Prislovje in metanje}

Prva skupina vprašanj po prislovju oziroma cirkumstantih (Nartnik 2002: 381) navaja na razlikovanje med časovnim prislovkom (Čp) nasproti srednjemu prislovku (Sp) in krajevnim prislovkom (Kp), druga skupina skupina vprašanj po metanju oziroma aktantih (Nartnik 2009: 69,73) pa navaja še na razlikovanje med formalnimi osebki kot osebnimi in stvarnimi soodvisnimi meti (Sm) nasproti logičnim osebkom kot osebnim vmesnim metom $(\mathrm{Vm}) \mathrm{v}$ tožilniku in osebnim dodatnim metom (Dm) v dajalniku (Vincenot 1975: 249):

PRISLOVJE:

POVEDEK:

METRNJE:

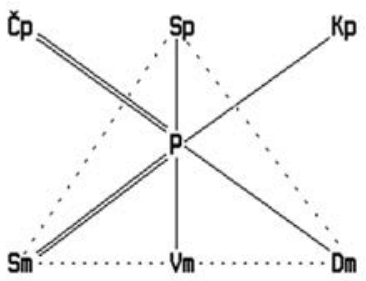

Pri formalnih osebkih je sicer važno že iskanje osebnih in stvarnih soodvisnih metov na ničelni stopnji $\emptyset$, podano v nasprotnih stavkih:

$$
\begin{aligned}
& \text { stegnitise } \rightarrow \text { Ta rajni Øje } \rightarrow \text { Kdo je ta rajni? } \\
& \begin{aligned}
& \rightarrow \text { On je ta rajni } \\
\text { stegnitise } \rightarrow \text { Vzelo } \emptyset \text { gaje } & \rightarrow \text { Kaj ga je vzelo? }
\end{aligned} \\
& \rightarrow \text { Vrag ga je vzel }
\end{aligned}
$$

Prvi stavek je pravzaprav odgovor na navadni glagol umreti, ki je kot tak bližji posmrtnemu zveličanju, izraženemu z nesrednjim spolom posamostaljenega pridevnika ta rajni in osebnega soodvisnega meta $\emptyset$ (Stramljič Breznik 1999: 275), medtem ko je drugi stavek ravno odgovor na ekspresivni, iztisni glagol stegniti se (Nartnik 2011: 155, 157), ki je kot tak bližji posmrtnemu pogubljenju, izraženemu s srednjim spolom opisnega preteklika vzeloje in splošnostvarnega soodvisnega meta $\emptyset$. Na nesrednji spol namreč kaže dodatno vprašanje prepoznave $\mathrm{z}$ iskalnoosebnim zaimkom $k d o$, na srednji spol pa dodatno vprašanje razpoznave $\mathrm{z}$ iskalnostvarnim 
$\hookrightarrow \quad$ zaimkom kaj (Nartnik 2007: 21, 22). Primerjava tudi kaže, kako se splošnostvarni [.] Soodvisni met $\emptyset$ drugega stavka načelno pozunanji v živi soodvisni met vrag naN sproti osebnemu vmesnemu metu ga. Splošnostvarni soodvisni met $\emptyset$ naslednjih $\mapsto \quad$ dveh stavkov pa se načelno pozunanji tako, da je vmes možno še ponotranjenje v neživi soodvisni met tres oziroma mraz (Běličová - Uhlířová 1996: 55, 56):

$$
\begin{array}{rll}
\text { mrzlica } & \rightarrow \text { Trese } \emptyset \text { ga } & \rightarrow \text { Kaj ga trese? } \\
& \rightarrow \text { Tres ga trese } & \rightarrow \text { Mraz ga trese } \\
\text { mrzlica } & \rightarrow \text { Mrazi } \emptyset \text { ga } & \rightarrow \text { Kaj ga mrazi? } \\
& \rightarrow \text { Mraz ga mrazi } & \rightarrow \text { Mraz ga ima }
\end{array}
$$

Neživi soodvisni met se z zunanje sile, kakor sta mraz ali voda, hočeš nočeš prenese kar na prizadeti del telesa (Žele 2007: 350), kakor sta golt in prst:

$$
\begin{aligned}
& \text { vodenica } \rightarrow \text { Zaliva } \emptyset \text { ga } \rightarrow \text { Kaj ga zaliva? } \\
& \rightarrow \text { Voda ga zaliva } \\
& \text { vodenica } \rightarrow \text { Nabira } \emptyset \text { se mu } \rightarrow \text { Kaj se mu nabira? } \\
& \rightarrow \text { Voda se mu nabira } \\
& \text { bezgavka } \rightarrow \text { Vkrofu } \emptyset \text { ga boli } \rightarrow \text { Kaj ga tam boli? } \\
& \rightarrow \text { Golt ga boli } \\
& \text { zanohtnica } \rightarrow \text { Gnoji } \emptyset \text { se mu } \rightarrow \text { Kaj se mu gnoji? } \\
& \rightarrow \text { Prst se mu gnoji }
\end{aligned}
$$

V zvezi s srednjimi prislovki (Sp) lahko del telesa celo prevlada. Na srednji prislovek kolikosti koliko se namreč navezuje mernoosebni soodvisni met ga v naslednjih dveh stavkih:

$$
\begin{array}{lll}
\text { suh } & \rightarrow \text { Sama kost in koža ga je } & \rightarrow \text { Koliko ga je? } \\
\text { trebušast } & \rightarrow \text { Samo kost in kožo Ø ima } & \rightarrow \text { Koliko česa } \emptyset \text { ima? } \\
& \rightarrow \text { Samo trebuh ga je } & \rightarrow \text { Koliko ga je? } \\
& & \rightarrow \text { Koliko česa } \emptyset \text { ima? }
\end{array}
$$

$\mathrm{Na}$ srednji prislovek kakovosti kako se spet navezujeta splošnostvarni soodvisni met $\emptyset$ in osebni dodatni met $m u$ ob zastopnem glagolu je (Kopečný 1962: 161, 173), kar se spet razveže v osebni soodvisni met $\emptyset$ ob povratnem glagolu se ima:

$$
\begin{aligned}
& \text { stegnitise } \rightarrow \text { Presvetlo } \emptyset \text { muje } \quad \rightarrow \text { Kako } \emptyset \text { mu je zdaj? } \\
& \rightarrow \text { Kako Ø se ima zdaj? } \\
& \text { stegnitise } \rightarrow \text { Odzvonilo Ømuje } \rightarrow \text { Kako Ømu je zdaj? } \\
& \rightarrow \text { Kako Ø se ima zdaj? }
\end{aligned}
$$

Razvezava zastopnosti razkriva osebno počutje, in to pri geslih, ki se nanašajo na človeka, niti ni nepričakovano. 


\section{Literatura}

Běličová - Uhliřrová 1996 = Helena Běličová - Ludmila Uhliirová, Slovanská věta, Praha: Euroslavica, 1996.

Kopečný 1962 = František Kopečný, Základy české skladby, Praha: Státní pedagogické nakladatelství, 1962.

Nartnik 2002 = Vlado Nartnik, Prislovna raba brezpredložnega tožilnika v Poezijah Franceta Prešerna, v: Med dialektologijo in zgodovino slovenskega jezika: ob življenjskem in strokovnem jubileju prof. dr. Martine Orožen, ur. Marko Jesenšek - Bernard Rajh - Zinka Zorko, Maribor: Slavistično društvo, 2002 (Zora 18), 381-389.

Nartnik 2007 = Vlado Nartnik, Slovniška razvrstljivost samostalnikov v Slovenščini za tujce, v: Besedje slovenskega jezika, ur. Marko Jesenšek, Maribor: Slavistično društvo, 2007 (Zora 50), 21-25.

Nartnik 2009 = Vlado Nartnik, K iskalnim vprašalnicam slovanskega jugozahoda, Riječ: časopis za slavensku filologiju (Rijeka) 15 (2009), št. 3, 68-74.

Nartnik 2011 = Vlado Nartnik, Leksem stegniti se v slovenskih narečjih, v: Narečna prepletanja, ur. Goran Filipi, Koper: Univerza na Primorskem, Znanstveno-raziskovalno središče - Univerzitetna založba Annales, 2011, 155-160.

Sicherl - Žele 2012 = Ava Sicherl - Andreja Žele, Slovensko-angleški glosar jezikoslovnega izrazja, Ljubljana: Oddelek za anglistiko in amerikanistiko - Oddelek za slovenistiko, 2012.

SLA 1.2 = Slovenski lingvistični atlas 1: človek (telo, bolezni, družina) 2: komentar$j i$, ur. Jožica Škofic, Ljubljana: Založba ZRC, ZRC SAZU, 2011 (Jezikovni atlasi).

Stramljič Breznik 1999 = Irena Stramljič Breznik, Prispevki iz slovenskega besedoslovja, Maribor: Slavistično društvo Maribor, 1999 (Zora 7).

Vincenot 1975 = Claude Vincenot, Essai de grammaire slovène, Ljubljana: Mladinska knjiga, 1975.

Zimek 1963 = Rudolf Zimek, Problematika spony v ruštině v porovnání s češtinou, Praha: Státní pedagogické nakladatelství, 1963.

Žele 2007 = Andreja Žele, Brezosebni glagoli in brezoseb(kov)na raba, v: Razprave razreda za filološke in literarne vede SAZU 20, Ljubljana: SAZU, 2007, $337-357$. 


\section{Describing diseases and death using logical subjects in the first volume of the Slovenian Linguistic Atlas}

\section{Summary}

The first volume of the Slovenian Linguistic Atlas refers to the semantic field 'man' - his body, diseases, and family. Nouns predominate among the entries denoting diseases and death; they are followed by adjectives (slightly fewer), and verbs (two).

In dialect responses to nonverbal questions, now and then an adjective appears in place of a noun and vice versa (the type vodenica 'edema' $\rightarrow$ biti vodeničen 'to be edematous' and trebušast 'with a large belly' $\rightarrow$ imeti trebuh 'to have a belly'). A similar quality is seen in descriptions that have a verbal phraseme in place of an expected noun, and also ellipsis with a more or less omitted verbal core (the type zanohtnica 'whitlow' $\rightarrow$ (gnojiti se) za nohtom '(to have an abscess) behind the nail'). The verbs themselves are generally given in the infinitive, but often appear in sentences with formal subjects as personal or non-personal first actants in opposition to logical subjects as personal second actants in the accusative and personal third actants in the dative. For formal subjects, the distinction between personal and non-personal first actants is already important at the null level $\emptyset$, given in counterposed sentences.

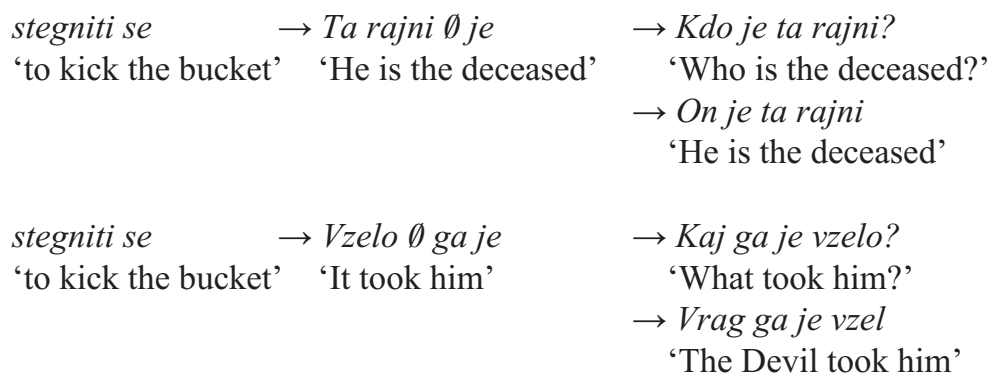

The nominalized adjective ta rajni 'the deceased' in the first sentence points to the personal first actant $\emptyset$ 'he', wheras the neuter gender of the past tense vzelo je 'took' in the second sentence indicates the ambient first actant $\emptyset$ 'it', which is in principle externalized in the animate first actant vrag 'the Devil' counterposed to the personal second actant $g a$ 'him'. 